\title{
Repliek op Van der Watt se artikel oor 'Intertekstualiteit en oorinterpretasie: Verwysings na Genesis 28:12 in Johannes 1:51?'
}

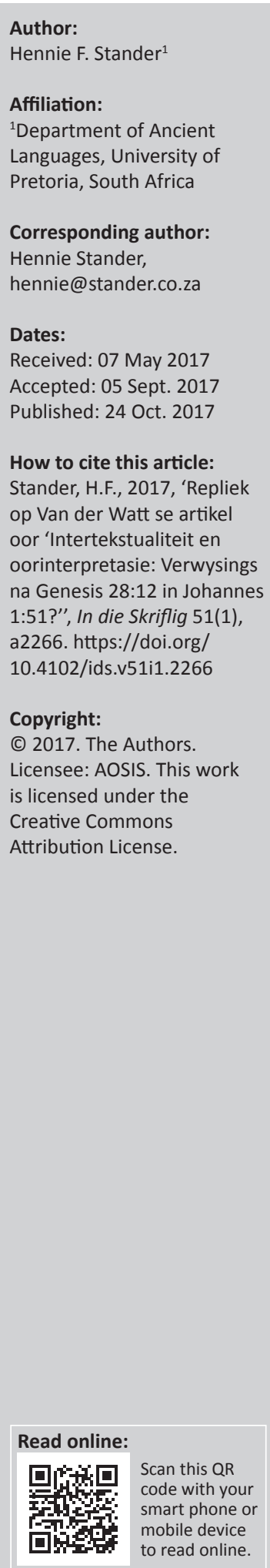

A response to Van der Watt's article on 'Intertextuality and over-interpretation: References to Genesis 28:12 in John 1:51?' This article is a response to an article of Van der Watt titled 'Intertextuality and over-interpretation: References to Genesis 28:12 in John 1:51?' (2016). He states in this article that his aim is 'to illustrate the dangers of over-interpretation when dealing with intertextual relations between texts, especially when allusion is assumed'. He then gives a brief survey of different interpretations of John 1:51. Van der Watt shows in his article how theologians use themes from Genesis 28:12 (like the ladder, Jacob or Bethel, which are not mentioned in John 1:51) in their expositions of John 1:51. Van der Watt regards some of these expositions as examples of over-interpretation. The aim of my article is to show how Church Fathers interpreted Genesis 28:12 and John 1:51. I show in my article that the Church Fathers saw several parallels between these two sections from the Bible. Furthermore, I suggest that the early theologians' interpretations formed a tradition that probably influenced modern interpreters of the Bible. I also discuss the role of typology in the history of interpretation, specifically also in the case of Genesis 28:12 and John 1:51. I then argue that it is perhaps not so far-fetched to see an intertextual relation between Genesis 28:12 and John 1:51.

\section{Inleiding}

Van der Watt (2016) ${ }^{1}$ wys in sy artikel ('Intertekstualiteit en oorinterpretasie: Verwysings na Genesis 28:12 in Johannes 1:51?') op die gevaar daarvan om 'n teks te 'oorinterpreteer' wanneer daar met intertekstualiteit tussen tekste omgegaan word - veral wanneer sinspeling veronderstel word. Om sy punt te staaf, gee hy dan voorbeelde van teoloë wat Johannes 1:51 in terme van Genesis 28:12 verklaar. Van der Watt sê dat die enigste raakpunt tussen die twee tekste (Gen 28:12 en Joh 1:51) die engele is wat opvaar en neerdaal - en spesifiek dan ook die onverwagte orde van die aksies, naamlik eers 'opvaar' en dan 'neerdaal'. Hy beklemtoon dat die ooreenkoms tussen hierdie twee tekste ook hier eindig. Hy beweer dat 'n hele klomp van die ander narratiewe gegewens in Genesis 28:12 nie in Johannes 1:51 voorkom nie, en selfs ook nie na verwys word nie. Van der Watt noem sake soos die leer, die aarde, 'n klip, 'n droom, die stem van God of reaksie op die stem van God. Verder, sê Van der Watt, is daar etlike elemente in Johannes se verhaal wat nie in die Genesis-verhaal voorkom nie. Hy redeneer dus dat Johannes se verhaal uniek is en dat die evangelis slegs een enkele aspek uit Genesis 28:12 wou beklemtoon, en dat hy nie die hele konteks van Genesis 28:12 met die verstaan van Johannes 1:51 wou integreer nie. Van der Watt argumenteer dat die funksie van die engele bloot die verwagting skep van God se teenwoordigheid. Hy sluit sy artikel af deur onder andere lesers te waarsku teen die gevare van oorinterpretasie van 'n teks. Hy wys daarop dat wanneer 'n mens 'n teks interpreteer, behoort die grense wat die teks self suggereer, gerespekteer word.

Met die kern van hierdie artikel kan daar nie fout gevind word nie. Dit is deeglik beredeneer en die oogmerk hiervan is om lesers op te roep om altyd die grense wat enige teks stel, te respekteer. Tog het ek twee leemtes in die artikel bespeur wat ek graag in hierdie artikel sal wil ondersoek. Ek beskou my artikel nie as 'n regstelling van die Van der Watt-artikel nie, maar bloot as 'n aanvulling.

Eerstens, Van der Watt bespreek die interpretasiegeskiedenis van Johannes 1:51. Hy wys hoe dit deur al die fasette van Genesis 28 se verhaal uitborduur word met die aanname dat Johannes 1:51 juis dít wil interpreteer. Wanneer Van der Watt sê dat hy 'n 'dwarssnit deur die interpretasiegeskiedenis van 1:51' (bl.4) gee, begin hy met die werke van Newman en Nida (1993:52) en Van Houwelingen (2007:77). Hy haal ook ander werke aan wat in die laaste 40 jaar 1.Alle verdere verwysings na Van der Watt word uit hierdie artikel aangehaal en sal slegs met bladsynommers aangedui word. 
verskyn het, soos dié van Attridge (2010:68), Barrett (1978:187), Brant (2011:54) en Knowles (2001:508). Die enigste ander 'ouer' eksegete wat hy aanhaal, is Pink (1923-1945:74) en Robertson (1916:49-51). Van der Watt sê inderdaad dat hy net 'n 'dwarssnit' deur die interpretasiegeskiedenis gee, maar ek dink dit sou die artikel baie verryk het om ook na die kerkvaders van die eerste eeue n.C. te kyk. Ek wil dus met my 'dwarssnit' poog om deur die interpretasiegeskiedenis van die betrokke deel die antieke teoloë se interpretasies by hierdie gesprek betrek. Hulle interpretasie het juis die tradisie geskep waaruit die latere eksegete moontlik geleen het om ooreenkomste tussen die twee tekste te sien. Van der Watt verwys slegs twee keer na 'n kerkvader: In die openingsreël van die artikel verwys Van der Watt na Klemens van Aleksandrië wat die Johannesevangelie as 'n 'geestelike Evangelie' bestempel het. Die tweede vermelding van 'n kerkvader is in ' $n$ voetnota waar hy na 'n opmerking van Brown (1971:90) rakende 'Justinus Triphos' verwys. Daar was egter nie 'n kerkvader met so 'n naam nie. Hierdie betrokke kerkvader staan bekend as Justinus die Martelaar, en een van sy geskrifte is getiteld 'Dialoog met die Jood Trypho'. Nietemin, in Van der Watt se artikel ontbreek daar 'n beskouing van die vroeë outeurs se hantering van Genesis 28:12 en Johannes 1:51. Natuurlik is dit onmoontlik om alles in een artikel te behandel, maar ek is oortuig dat 'n oorsig oor die Vroeë Kerk se hantering van hierdie twee teksgedeeltes wel Van der Watt se artikel kan verruim, aangesien dit kan wys hoe moderne outeurs bloot vroeë interpretasies van die teks voortsit - of ten minste daardeur beïnvloed is.

Die tweede aspek wat ek in hierdie artikel wil hanteer, is die kwessie van tipologie. Intertekstualiteit is 'n baie breë term wat tipologie insluit. Ek het dit nogal vreemd gevind dat ek nêrens die woord tipologie in Van der Watt se artikel teëgekom het nie (behalwe een keer die woord anti-tipe op bl. 4).

\section{Die antieke teoloë se hantering van die twee verhale}

Wanneer 'n mens wel na die vroeë teoloë se geskrifte kyk, is dit duidelik dat die antieke teoloë graag 'n verband tussen Genesis 28:12 en Johannes 1:51 getrek het. Die antieke teoloë het vir geen oomblik daaraan getwyfel dat die gebeure van Genesis 28 tipologies na die gebeure van Johannes 1:51 heengewys het nie. Verder het hulle natuurlik die verhaal ryklik borduur met hulle interpretasies, terwyl hulle allerhande 'verbande' tussen die twee verhale raakgesien het. Chrysostomos (In Ep. ad Col., MPG 62.336.58-59) bestempel Jakob se leer nie verniet as die 'teken der tekens'

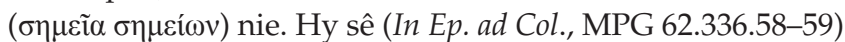
die verhaal van Jakob en die leer 'vind misterieus plaas as 'n

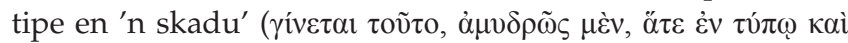

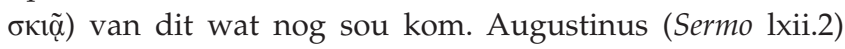
noem ook hierdie gebeure 'n 'groot misterie' en sê dat 'n mens (= Jakob) se droom nie opgeteken sou word indien dit nie na 'n groot misterie heengewys het nie. Hy sê daar was 'n profesie in die visioen opgesluit. Jakob het wel verstaan wat hy gesien het en dit is dan ook waarom hy die klip gesalf het. Hy het geweet dat dit na die Gesalfde verwys.
Ook Ambrosius (De Jacob et Vita Beata, ii, PL 14.651A-B) sê dat toe Jakob die engele op die leer gesien het hy eintlik 'voor die tyd reeds Christus op die aarde gesien het' (Christum praevidit in terris) na wie 'n skare (caterva) engele af- en opgeklim het (Joh 1:51). Johannes van Damaskus (Oratio Prima in Dormitionem Sanctae Dei Genitricis Mariae 41-51) gaan so ver as om Jakob se leer as ' $n$ 'openbare aankondiging en ' $n$ tipe'

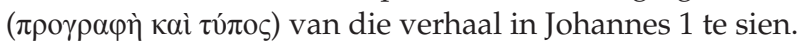

Gregorius Nazianzus (Oratio 2, xviii) sê ook dat die rots wat Jakob gesalf het, heenwys na die Rots wat vir ons gesalf is. Augustinus (De Civitate Dei xvi.38) sê dat Jakob olie uitgegiet het op die klip wat as sy kopkussing gedien het. Hy sê dan dat Jakob dit gedoen het 'omdat die naam Christus van die woord "salwing" afgelei is' (sed quoniam Christi nomen a chrismate est). Augustinus sê dat die 'Heiland self vir ons hierdie gebeure in die Evangelie in herinnering geroep het' (Saluator nobis in memoriam reuocare in euangelio) toe Hy vir Natanael gesê het: 'Hier is 'n ware Israeliet, 'n man in wie daar geen bedrog is nie' (Joh. 1:47). Dan wys Augustinus daarop dat Jakob wat die visioen in Genesis 28 gesien het, ook die naam Israel gehad het, en in Johannes 1:47 verwys Jesus ook na 'n Israeliet. Augustinus redeneer dus dat Jesus self hierdie verband tussen die twee verhale getrek het. Augustinus (De Civitate Dei xvi.38) kom dan tot die gevolgtrekking dat hier beslis op iets gesinspeel word wat 'betrekking het op die groot misterie' (ad magnum pertineat sacramentum). Ook Chrysostomos (De Lazaro, MPG.48.973.47) bestempel Jakob se klip as 'n 'geestelike

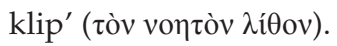

Augustinus verduidelik elders (Contra Faustum xii, 26) ook dat Christus self na Jakob se verhaal verwys in sy gesprek met Natanael. Augustinus gaan so ver as om te sê dat Christus die verhaal van Jakob in die Evangelie ophaal en dit dan 'baie duidelik verklaar as 'n tipe van Homself' (et de se figuratum apertissime testificans). Net soos Jakob met sy kop op 'n klip gelê het, so het Natanael ook by wyse van spreke sy kop op Christus, die Rots, gelê toe hy bely het dat Christus die Seun van God is en die Koning van Israel.

Augustinus sien egter nog ooreenkomste tussen Jakob en Natanael, en dus tussen Genesis 28:12 en Johannes 1:51, omdat Natanael ook in laasgenoemde episode figureer. Hy sê (Sermo 39.5) dat Jakob iemand 'sonder bedrog' (sine dolo) was, en Jesus bestempel Natanael ook as iemand 'sonder bedrog'

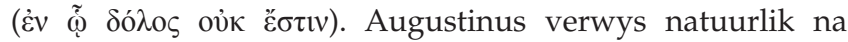
Genesis 25:27 waar Jakob as 'n 'vredeliewende man' bestempel word.

Die Vulgaat noem Jakob 'n 'opregte mens' (vir simplex), maar Augustinus verander dit gerieflikheidshalwe na 'sonder bedrog' (sine dolo). Die Septuaginta bestempel Jakob in

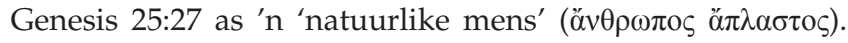
Hierdie beskrywings van Jakob se karakter verbind ook die twee verhale van Genesis 28:12 en Johannes 1:51 met mekaar (volgens die kerkvaders). Dit staan nou wel nie in dieselfde vers nie, maar daar moet in gedagte gehou word dat wanneer die antieke teoloë 'n teks aangehaal het, hulle die verband 
baie wyer as bloot daardie aangehaalde teks gesien het. Stegner (1990:7) wys daarop dat wanneer kerkvaders woorde of verse aangehaal het, die afhanklikheid van daardie teks ver meer is as bloot die individuele woorde, aangesien die hele konteks bedoel is. Scacewater (2013:136) sê dat Nuwe Testament outeurs dikwels 'n enkele vers aanhaal as 'n aanwyser na die hele konteks. Scacewater weerlê dus per implikasie Van der Watt se siening omdat laasgenoemde nie buite die aangehaalde vers vir parallelle wil soek nie. Scacewater (2013:142) argumenteer byvoorbeeld dat die Johannesevangelie die Joodse verwerping van Jesus se bediening sien as die tipologiese vervulling van Jesaja se bediening wat ook verwerp is.

Die kerkvaders het natuurlik etlike ander ooreenkomste tussen Jakob en Jesus gesien wat dit nog makliker gemaak het om Genesis 28:12 en Johannes 1:51 met mekaar te verbind. Ambrosius (De Excessu Fratris sui Satyri 2.100) noem Jakob eksplisiet "n tipe van Christus' (Jacob typum Christi). Hy sê dat net soos Jakob aan sy sy beseer is (Gen 32:25), is ook Christus aan die kruis aan sy sy beseer (Joh 19:34). Augustinus sê dat die klip wat Jakob gesalf het die 'klip wat deur die bouers verwerp is' (Sermo 72.2).

Die feit dat die Septuaginta in Genesis 28:13 praat van die кúpros wat aan die bopunt van die leer gestaan het, het dit maklik gemaak om dit na Jesus toe deur te trek. So sien ons byvoorbeeld dat ' $n$ Jood en 'n Christen in gesprek is met mekaar in die Dialogus Timothei et Aquilae 21.12 (sien die Griekse teks hiervan in Robertson 1986). Die Christen verduidelik aan die Jood dat ' $n$ mens reeds in die boek Genesis lees van die kruis van Jesus en dan verwys hy na die verhaal van Jakob. Hy gaan voort deur te sê dat 'n mens moet verstaan dat Jesus sy kruis as 'n herderstaf gebruik het. Christus staan dus bo-aan die Jakob-leer asof Hy op sy herderstaf leun.

Van der Watt (bl. 4) sê ook 'die Seun vervul nie die funksie van die leer nie, maar die plek waarheen en van waar die beweging plaasvind'. Die kerkvaders het egter 'n ander standpunt gehuldig. Vir hulle was Jesus die leer in Genesis 28 sowel as in Johannes 1:51. Augustinus het geen twyfel dat die leer wel Christus is nie. Immers, so redeneer Augustinus (Contra Faustum xii.26), Jesus het dit mos duidelik gemaak dat Hý self die leer is, want Hy sê dan self 'Ek is die Weg' (ego sum via). Dit is ook Tertullianus (Adversus Marcionem 3.24) se standpunt, naamlik dat Jakob se leer geïnterpreteer moet word as Christus wat die weg na die hemel aandui.

Van der Watt (bl. 4) wys ook daarop dat terwyl Genesis 28:1 die frase $\dot{\varepsilon} \pi$ ' $\alpha \hat{\tau} \tau \tilde{\varsigma} \varsigma$ [daarop] gebruik en dat dit na $\kappa \lambda \dot{\mu} \mu \alpha \xi$ [leer] verwys, sommige teoloë ook 'n leer in Johannes 1:51 wil inlees, terwyl daar nie sprake van 'n leer is nie. Hy sê voorts dat die woord غ̇ $\pi$ í met werkwoorde van beweging nie 'n rusplek kan aandui nie, maar bloot die plek merk ván waar en waarná die beweging plaasvind. By die kerkvaders is daar egter geen konsekwente gebruik van voorsetsels nie. Die Latynse kerkvaders wat 'n groot invloed op die Westerse vertolking van bogenoemde twee verhale uitgeoefen het, het dikwels voorsetsels met die grootste gemak uitgeruil. Die Vulgaat gebruik die voorsetsel supra in Johannes 1:51 en sê dat die engele opgeklim het 'supra Filium hominis'. Augustinus (Tract. in Ev. Joh. vii.22) haal egter dieselfde vers aan en praat van 'super filium hominis'. Elders sê Augustinus (Contra Faustum xii.26) dat die engele se opklim en afklim op die leer is nie net 'na Hom' (ad ipsum) nie, maar ook 'deur Hom' (per illum). In sy Sermo 39.5 sê Augustinus ook dat die engele 'na die Seun van die mens toe' (ad Filium hominis) geklim het.

Van der Watt (bl. 1) sê dat die enigste raakpunt tussen Genesis 28:12 en Johannes 1:51 die verwysing na die engele wat opvaar en neerdaal is, en in albei die tekste kom daar 'n onverwagte orde van die twee aksies voor. Die ongewone volgorde van die engele se 'opgaan' en afgaan' teen die leer het dit inderdaad ook vir die kerkvaders maklik gemaak om hierdie twee verhale met mekaar te verbind. Hierdie ongewone volgorde was ook vreemd vir die antieke teoloë en hulle het dikwels daaroor kommentaar gelewer, maar hulle het ook probeer om teologies daarvan sin te mak. So sien ons byvoorbeeld dat ' $n$ Jood en 'n Christen in gesprek is met mekaar in die Dialogus Timothei et Aquilae 21.12. In hierdie gesprek wys die Christen op die eienaardigheid dat 'n mens eers lees van 'opgaan' en dan 'afgaan' en nie andersom nie. Hy verduidelik dat dit bloot so is, aangesien die kruis, net soos die leer in die verhaal van Jakob, op die aarde geplaas is. Christus kon dus dadelik die heidennasies op aarde ontvang en verwelkom en het toe onmiddellik 'opgegaan'. Dit het die Jood nuuskierig gemaak oor wie diegene dan is wat teen die leer afklim. Die Christen verduidelik toe dat dit die Jode is wat ongehoorsaam is en Christus nie aanvaar het nie. Hulle gaan af, terwyl die heidennasies wat glo, 'opgaan'.

Chrysostomos (In Ascensionem Domini Nostri Jesu MPG 50.449.17-25) gee 'n ander verklaring vir die omkering van die werkwoorde. Vir hom dui dit alles op die gretigheid en ongeduld van die engele om 'n mens in die hemel te sien. Hulle maak presies soos dit die gewoonte is by mense wat liefhet en wat nie kan wag nie, maar die tyd wil aanjaag! Daarom klim hulle op en af op die leer. Die engele wat opklim is volgens hom die evangeliste en predikers wat oor Christus vertel. Wanneer die engele 'opklim', is dit om die majesteit en goddelike natuur van Christus deur wie alles geskape is te verkondig. Wanneer hulle 'afklim', is dit om te vertel van Christus wat uit 'n vrou gebore is ten einde die mens wat onder die wet leef te verlos. Dit was ook geen probleem om by verskillende geleenthede verskillende verklarings vir dieselfde saak te gee nie. So byvoorbeeld reken Augustinus (Tract. in Ev. Joh. vii.22) ook dat die engele wat teen die leer op- en afklim goeie predikers is wat Christus verkondig. Origenes (Comm. in Ep. ad Rom. i, PG 14.855A) dink weer dat die engele wat so op- en afklim bloot hulle opgewondenheid en blydskap te kenne wil gee oor die Romeine wat tot geloof gekom het. Jesus vertel mos in een van sy gelykenisse hoe bly die engele is 'oor een sondaar wat hom bekeer' (Luk 15:10). Om die grootsheid van die gebeure verder te beklemtoon, sê Origenes (In Ezech. PG 13.674C) dat die engele nie net uit een hemel kom nie, maar vanuit baie hemele! 
Natuurlik is etlike van bogenoemde interpretasies vergesog, maar vir die antieke eksegeet het die teks geen grense gehad nie. Trouens, Ou-Testamentiese tekste hoef ook nie net na die Nuwe Testament te verwys het nie, maar kon selfs ook na heidense tekste verwys. Origenes (Contra Celsum vi.21) verduidelik byvoorbeeld dat die engele wat op- en afgeklim het teen die leer, moontlik ook kon verwys na Plato se lering

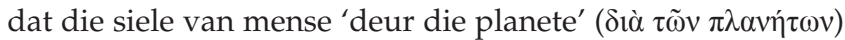
na en van die aarde kan beweeg. Origenes voeg egter dadelik by dat hierdie verhaal 'op ' $n$ misterieuse wyse na veel groter

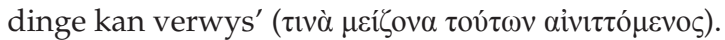

Vir Chrysostomos (In Ep. ad Col., hom. v, MPG 62.331.1762.333.97) was dit alles bloot 'n bewys van dit wat Paulus in Kolossense 1:26 gesê het, naamlik dat 'dit die geheimenis is wat eeue en geslagte lank verborge was, maar wat nou geopenbaar is aan die mense wat aan Hom behoort'. Hy redeneer verder dat God dikwels sy waarheid tipologies geleidelik aan ons openbaar. Chrysostomos sê dat ons nie altyd met tipologie sommer direk van die $\mathrm{Ou}$ na die Nuwe Testament kan spring nie. Hy verduidelik byvoorbeeld dat Henog se opname na die hemel ons voorberei het vir Elia se opname na die hemel en so is ons geleidelik voorberei vir Jesus se hemelvaart. Hy gebruik 'n verdere voorbeeld om dit te illustreer: Noag is in 'n ark opgesluit. Dit het ons voorberei vir Jona wat in 'n vis opgesluit is en dit het natuurlik weer heengewys na Christus in die graf. Chrysostomos (In Ep. ad Col., hom. v, MPG 62.336.53-57) sê verder dat tipologie soos 'n leer werk: 'n mens klim trappie vir trappie al hoër. Jy kan byvoorbeeld nie van die eerste trappie direk na die vierde klim nie.

\section{Intertekstualiteit en tipologie}

Soos hierbo reeds genoem, argumenteer Van der Watt dat teoloë hulle hand oorspeel wanneer hulle Johannes 1:52 wil verklaar deur Genesis 28:12 intertekstueel in hulle interpretasie te betrek. Hy sê 'die grootste hoeveelheid van die narratiewe gegewens uit Genesis 28:12 kom nie in 1:51 voor nie. Die ooreenkomste is veel minder as wat moderne teoloë wil raaksien' (bl. 1). Eerstens is hierbo reeds aangetoon dat die vroeë kerkvaders natuurlik talle ooreenkomste tussen hierdie twee verhale gesien het en dat hulle sonder om een oomblik te huiwer Genesis 28:12 tipologies verklaar het as 'n heenwyse na Johannes 1:51. 'n Mens kan net aanneem dat hierdie tradisie baie sterk bly voortbestaan het in die Nachwirkung van hierdie twee verhale. Tweedens, 'n mens moet onthou dat antieke skrywers baie wyer as enkele verse vir parallelle gesoek het. Hulle het die parallelle in verhale gesoek en nie net op enkele verse gefokus nie.

In die afgelope eeu is daar al talle werke geskryf oor die (on) geldigheid van tipologie as metode van eksegese. Goppelt (1982:177) het tipologie gedefinieer as 'a prefiguration in a different stage of redemptive history that indicates the outline or essential features of the future reality and that loses its own significance when the reality appears'. Woollcombe (1957) het tipologie soos volg van allegorie onderskei:
Typological exegesis is the search for linkages between events, persons or things within the historical framework of revelation, whereas allegorism is the search for a secondary and hidden meaning underlying the primary and obvious meaning of a narrative. (p. 40)

VanMaaren (2013:277) wys weer op 'n ander baie duidelike verskil wat daar tussen tipologie en allegorie bestaan. Hy sê dat tipologie, anders as allegorie, in die geskiedenis geanker is.

Deur die eeue heen is daar op talle maniere probeer om 'n brug te slaan tussen die Ou en Nuwe Testament om sodoende by een Christologiese boodskap uit te kom (Bird 2000:36). Dit is gebou op die veronderstelling dat die $\mathrm{Ou}$ en Nuwe Testament 'n eenheid vorm. Ondanks die Alexandrynse en die Antiocheense skool se teenstrydige benadering tot bybelse uitleg, het albei skole saamgestem dat die Ou sowel as die Nuwe Testament 'n eenheid vorm, en dat alles heenwys na Christus. Tipologie as eksegetiese model het dus 'n belangrike rol gespeel by antieke teoloë om hierdie doel te vervul (Gundry 1969:234). Natuurlik het die antieke teoloë dikwels hierdie tipes eerder geskep as ontdek! (Gundry 1969:235). Dit is ook net ' $n$ baie klein stappie verder om by allegorie uit te kom.

Of daar nou saamgestem word daarmee of nie, die realiteit is dat tipologie as metode van eksegese in die Ou sowel as die Nuwe Testament voorkom. Dentan (1952) wys byvoorbeeld hoe Jesaja 43:16-19 God se redding van Israel uit Egipte gebruik as 'n tipe van God wat sy volk weer sal uitlei. Die nuwe eksodus sal nie net soos die vorige wees nie, maar selfs nog groter (vgl. Jes 43:18).

Von Rad (1961:177) glo dat die Nuwe-Testamentiese skrywers soms uitdruklik en soms baie subtiel gebeure parallel met Ou-Testamentiese gebeure beskryf, en hulle neem aan dat die leser dit sal weet. Talle voorbeelde van tipologie kan dus in die Nuwe Testament onderskei word. Romeine 5:14 sê

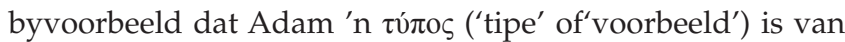
Hom wat sou kom. Meer spesifiek, etlike voorkomste van tipologie kan ook in die Evangelie van Johannes onderskei word. Enz (1957:208) sê byvoorbeeld dat tipologie van 'n gebeurtenis en 'n persoon tot 'n literêre vorm kan strek. Hy noem dan dat die Evangelie van Johannes 'n goeie voorbeeld van laasgenoemde is. Hy sê dat die Evangelie van Johannes 'n tipologiese verlenging van die boek Eksodus is. Cahill (1982:272) wys op verskeie voorbeelde van implisiete tipologie in die Nuwe Testament, en spesifiek ook in die Johannesevangelie. ' $n$ Goeie voorbeeld is Johannes 3:14: 'Soos Moses die slang in die woestyn hoog op 'n paal gesit, so moet die Seun van die mens verhoog word' (Joh 6:31-33 en 49-51 word ook as voorbeelde aangehaal). Ook Hoskins (2009:299) beskou die Pasga-gebeure as belangrike tipologiese gebeure wat in ag geneem moet word by die interpretasie van die Evangelie van Johannes.

Neyrey (1982:589) sê dat dit algemeen aanvaar word dat Johannes 1:51 op een of ander wyse na Jakob se verhaal in 
Genesis 28:12 verwys. Neyrey (1982:590) meen egter dat die saak wat hierdie twee insidente met mekaar verbind, is nie 'Jakob vs Jesus' nie. Dit is 'Jakob vs die dissipels' omdat, net soos wat die Here in Genesis 28 aan Jakob verskyn het, sal die Here in 'n teofanie aan die dissipels verskyn. Ook Kim (2015:226) voer aan dat Johannes 1:51 'n eskatologiese verwysing is na Genesis 28:12.

Neeb (1992:86-87) is oortuig dat die Johannesevangelie doelbewus tipologiese lyne tussen Jakob en Jesus trek. In Johannes 4:12 sê die Samaritaanse vrou byvoorbeeld vir Jesus: 'Jy is tog nie groter as ons voorvader Jakob nie.' Die gebeure speel ook af by Jakob se put (Joh 4:6) op die grond wat Jakob aan sy seun Josef gegee het (Joh 4:5). Net soos Jakob, het ook Jesus moeg by die put aangekom (Joh 4:6). Neeb (1992:87-88) sluit af deur te sê dat die Johannesevangelie doelbewus probeer om 'n 'Jakob vs Jesus'-tipologie daar te stel om sodoende te wys dat Jesus Jakob eintlik oortref.

Ek besef dat daar al eeue lank 'n debat oor die geldigheid of waarde van tipologie en allegorie gevoer word. Gewoonlik word tipologie voorgehou as 'n aanvaarbare vorm van nieletterlike eksegese, terwyl allegorie dit juis nie is nie (vgl. Maartens 2008:288-289). Ondanks die feit dat Young (1997:193) haar voorbehoude het oor die onderskeid wat tussen allegorie en tipologie gemaak word, glo sy dat tipologie steeds ' $n$ nuttige term is. Maartens (2008:286) sê dat ongeag of ' $n$ mens tipologie se herkoms in Matteus of in Johannes moet gaan soek, was dit nog altyd deel van die kerk se tradisie.

\section{Gevolgtrekking}

Van der Watt se artikel is waardevol en hy maak 'n baie geldige punt wanneer hy aanvoer dat teoloë dikwels tekste oorinterpreteer wanneer daar met intertekstualiteit omgegaan word. Tog blyk dit duidelik uit bogenoemde dat die kerkvaders talle lyne tussen Genesis 28:12 en Johannes 1:51 getrek het. Die antieke teoloë het geen twyfel gehad dat Genesis 28:12 'n tipologiese heenwysing was na Johannes 1:51 nie. Dit is ook interessant dat hierdie siening deur Westerse kerkvaders (soos Augustinus) sowel as Oosterse kerkvaders (soos Chrysostomos) gehuldig is. Dit blyk ook dat die kerkvaders se interpretasie neerslag in moderne teoloë se interpretasie van Genesis 28:12 en Johannes 1:51 gevind het (soos gesien kan word in die voorbeelde wat Van der Watt in sy artikel gegee het). Natuurlik kan ons nie al die parallelle aanvaar wat die kerkvaders tussen bogenoemde verhale aangetoon het nie. Tog aanvaar etlike moderne teoloë dat daar in die Johannesevangelie (soos in die res van die Nuwe-Testament) voorbeelde van tipologie voorkom. Dit is ook so dat die Evangelie van Johannes wel ook eksplisiete parallelle tussen Jakob en Jesus (Joh 4) trek. Dit is verder belangrik om te onthou dat tipologie dikwels wyer as bloot die aangehaalde vers strek en dat die hele verhaal dikwels as verwysing geneem word, selfs al word net 'n enkele vers aangehaal. Wanneer al bogenoemde argumente in ag geneem word, is dit regtig so vergesog om Genesis 28:12 te betrek by die interpretasie van Johannes 1:51?

\section{Erkenning Mededingende belange}

Die outeur verklaar dat hy geen finansiële of persoonlike verbintenis het met enige party wat hom nadelig kon beïnvloed het in die skryf van hierdie artikel nie

\section{Literatuurverwysings}

Attridge, H., 2010, 'Genre bending in the Fourth Gospel', in H. Attridge (ed.), Essays on John and Hebrews, pp. 31-45, Mohr Siebeck, Tübingen.

Barrett, C.K., 1978, The Gospel according to St John, Society for promoting Christian Knowledge, London.

Bird, C.L., 2000, 'Typological interpretation within the Old Testament: Melchizedekian typology', Concordia Journal 26(1), 36-52.

Brant, J-A., 2011, John, Baker Academic, Grand Rapids, MI.

Brown, R.E., 1971, The Gospel according to John (i-xii), vol. 1, Geoffrey Chapman, London.

Cahill, P.J., 1982, 'Hermeneutical implications of typology', The Catholic Biblical Quarterly 44(2), 266-281.

Dentan, R.C., 1952, 'Typology-Its use and abuse', Anglican Theological Review 34(4), 211-217.

Enz, J.J., 1957, 'The book of Exodus as a literary type for the Gospel of John', Journa of Biblical Literature 76(3), 208-215. https://doi.org/10.2307/3261570

Goppelt, L., 1982, Typos: The typological interpretation of the Old Testament in the New, Eerdmans, Grand Rapids, MI.

Gundry, S.N., 1969, 'Typology as a means of interpretation: Past and present', Journal of the Evangelical Theological Society 12(4), 233-240.

Hoskins, P.M., 2009, 'Deliverance from death by the true passover lamb: A significant aspect of the fulfilment of the passover in the Gospel of John', Journal of the Evangelical Theological Society 52(2), 285-299.

Kim, J., 2015, 'John 1:51 and the Motif of “Jacob's Ladder" in Genesis 28:12', PhD dissertation, New Testament Studies, Faculty of Theology, University of Pretoria.

Knowles, A. (ed.), 2001, The Bible guide, Augsburg, Minneapolis, MN.

Maartens, P.W., 2008, 'Revisiting the allegory/typology distinction: The case of origen', Journal of Early Christian Studies 16(3), 283-317. https://doi.org/10.1353/ earl.0.0193

Neeb, J.H.C., 1992, 'Jacob/Jesus typology in John 1,51', Proceedings: Eastern Great Lakes \& Midwest Biblical Society 12, 83-89.

Newman, B.M. \& Nida, E.A., 1993, A handbook on the Gospel of John, United Bible Societies, New York.

Neyrey, J.H., 1982, 'The Jacob Allusions in John 1:51', The Catholic Biblical Quarterly $44(4), 586-605$.

Pink, A.W., 1923-1945, Exposition of the Gospel of John, Bible Truth Depot, Swengel, PA.

Robertson, A.T., 1916, The divinity of Christ in the Gospel of John, Fleming H. Revell, Edinburgh.

Robertson, R.G., 1986, 'The dialogue of Timothy and Aquila: A critical text, Introduction to the manuscript evidence, and an inquiry into the sources and literary relationships', Th.D Dissertation, Harvard University, Cambridge, MA.

Scacewater, T.A., 2013, 'The predictive nature of typology in John 12:37-43', Westminster Theological Journal 75(1), 129-143.

Stegner, W.R., 1990, 'The temptation narrative: A study in the use of scripture by early Jewish Christians', Biblical Research 35, 5-17.

Van der Watt, J., 2016, 'Intertekstualiteit en oorinterpretasie: Verwysings na Genesis $28: 12$ in Johannes 1:51?', In die Skriflig 50(3), 6. https://doi.org/10.4102/ids. v50i3.2114

Van Houwelingen, P.H.R., 2007, Johannes, Kok, Kampen.

VanMaaren, J., 2013, 'The Adam-Christ typology in Paul and its development in the Early Church Fathers', Tyndale Bulletin 64(2), 275-297.

Von Rad, G., 1961, 'The interpretation of the Old Testament', Interpretation 15(2), 174-192. https://doi.org/10.1177/002096436101500205

Woollcombe, K.J., 1957, 'The biblical origins and patristic development of typology', in G.W.H. Lampe \& K.J. Woollcombe (eds.), Essays on typology, pp. 39-75, Allenson, Naperville, IL.

Young, F.M., 1997, Biblical exegesis and the formation of Christian culture, Cambridge University Cambridge. https://doi.org/10.1017/CBO9780511583216 